\title{
SISTEM PENJUALAN DAN DELIVERY PADA RESTORAN MARTABAK KUBANG DENGAN METODOLOGI BERORIENTASI OBJEK
}

\author{
Gilang Ryan Fernandes \\ Program Studi Informatika, Universitas Indraprasta PGRI \\ gilang.fernandes@gmail.com
}

\begin{abstract}
Abstrak
Penjualan dan delivery pada Restoran Martabak Kubang masih menerapkan sistem secara manual, mengakibatkan proses penjualan dan delivery menjadi kurang akurat dan tidak efektif dalam pembuatan laporan sehingga sulit mengambil keputusan. Tujuan dalam penelitian ini adalah untuk menanggulangi masalah yang terdapat pada Restoran Martabak Kubang dengan cara merancang sistem penjualan dan delivery. Metodologi yang digunakan pada penelitian ini menggunakan pendekatan kualitatif, yaitu dengan mengumpulkan data yang ada pada Restoran Martabak Kubang sehingga data tersebut dapat diteliti untuk diselesaikan masalahnya. Dengan adanya sistem ini diharapkan dapat membantu dalam pengambilan keputusan yang cepat, tepat dan akurat guna menyelesaikan masalah-masalah kompleks dan untuk menunjang kemajuan bagi Restoran Martabak Kubang.
\end{abstract}

Kata Kunci : Aplikasi, Penjualan, Delivery, Berorientasi Objek

\begin{abstract}
The sale and delivery of product at Martabak Kubang Restaurant still apply a manual system, leading to a less accurate sale and delivery process and to a time-consuming reporting process that make a decision-making difficult to do. The purpose of this research is to overcome the problems found in Martabak Kubang Restaurant by designing a sale and delivery system. The method used in this study is a qualitative approach by which the data on Martabak Kubang Restaurant are collected and researched to resolve the existing problems. The system is expected to assist in creating a fast, precise and accurate decision-making in order to solve complex problems and to facilitate the progress for Martabak Kubang Restaurant.
\end{abstract}

Keywords : Application, Sales, Delivery, Object Oriented

\section{PENDAHULUAN}

Pada saat ini sistem sangat diperlukan dalam menjalankan bisnis dan kepeluan lainnya. sistem sebagai sekumpulan komponen yang saling berhubungan dengan batasan yang jelas, bekerja bersama untuk mencapai tujuan bersama dengan menerima input serta menghasilkan output dalam proses transformasi teratur. Sistem memiliki tiga fungsi dasar, yaitu: input, process, output [1].

Mengingat restoran Martabak Kubang masih menerapkan sistem secara manual, sehingga mengakibatkan proses penjualan menjadi kurang akurat, kurang cepat dan kurang tepat. Sehingga masalah yang dihadapi pada restoran Martabak Kubang saat ini adalah:

1. Pemeliharaan data yang seadanya, sehingga mempersulit pemilik perusahaan untuk mengolah data.

2. Penyimpanan data yang kurang baik. Hal ini dibuktikan dengan adanya data yang sering hilang karena data yang disimpan masih dalam bentuk kertas (hard copy).

3. Kurang mengetahui penggunaan surat jalan, sehingga tidak dapat mengetahui total pengiriman secara benar.

4. Waktu yg dibutuhkan dalam akses data yang lama. 
Oleh karena itu dengan penerapan teknologi informasi yang dilakukan dapat memberikan manfaat bagi Restoran Martabak Kubang dalam menjalankan proses bisnisnya menjadi lebih cepat dan tepat serta mengurangi adanya human error sehingga dapat meningkatkan mutu dan kualitas terhadap perusahaan serta pelayanan terhadap pelanggan. Agar tidak menyimpang dari pokok pembahasan penelitian ini, penulis memfokuskan masalah pada sistem informasi penjualan dan delivery. Untuk menyelesaikan penelitian, penulis membutuhkan data-data yang sesuai pada sistem yang akan dianalisa dan dibahas dalam topik ini.

\section{METODE PENELITIAN}

Sesuai pada sistem yang akan dianalisa dan dibahas dalam topik ini. Penulis mengumpulkan data dengan beberapa metode penelitian, diantaranya adalah sebagai berikut:

\section{A. Rancangan Kegiatan}

Rancangan kegiatan dalam penelitian ini antara lain :

1. Menganalisa sistem, yaitu mempelajari dan mengetahui secara langsung apa yang dikerjakan pada sistem yang berjalan saat ini.

2. Men-spesifikasikan sistem, yaitu menspesifikasikan masukan yang digunakan, database yang ada, proses yang dilakukan dan keluaran yang dihasilkan oleh sistem.

3. Rancangan sistem, yaitu merancang sistem secara rinci berdasarkan hasil analisa sistem yang ada, sehingga menghasilkan model sistem baru yang diusulkan, dengan disertai rancangan database dan spesifikasi program.

\section{B. Teknik Pengumpulan Data dan Analisis Penelitian}

Pada tahap awal ini dilakukan pengumpulan data dan analisis penelitian dengan cara:

1. Tinjauan Lapangan

Penulis mengumpulkan data yang langsung diperoleh dari hasil penelitian langsung pada restoran Martabak Kubang.

Tinjauan lapangan dilakukan secara langsung dengan dua cara, yaitu:

a) Pengamatan

Pengamatan ini sangat diperlukan untuk melihat dan juga mengetahui secara langsung ke lokasi bagaimana proses bisnis yang terjadi dan juga mengamati proses sistem yang sedang berjalan saat ini.

b) Wawancara

Pada tahap wawancara dilakukan untuk mendapatkan data-data secara langsung dari sumbernya dengan tanya jawab secara interaktif dengan harapan informasi yang diperoleh benar.

2. Penelitian Kepustakaan

Penulis menggunakan berbagai sumber bacaan untuk mendapatkan informasi yang erat hubungannya.

\section{Analisa Berorientasi Obyek}

Istilah pendekatan objek mulai dikenal pada awal tahun 1967, melalui bahasa pemrograman yang bertujuan sebagai pemodelan atau simulasi. Dalam pendekatan berorientasi objek data direpresentasikan sebagai sebuah objek, baik dalam hal pengaksesannya maupun dalam hal pemodelannya. Program dan data yang dirancang terintegrasi dengan baik sehingga proses penyimpanan dan pengambilan data jauh lebih sederhana. Hal tersebut dikarenakan pemrogram tidak perlu lagi menguraikan objek ke tabel, memikirkan relasi antar tabel, dan sebaliknya karena program langsung mengakses data dengan objeknya [2]. Analisa berorientasi obyek adalah pendekatan yang digunakan untuk:

1. Investigasi masalah untuk menemukan (mengidentifikasikan) dan mendefinisikan objek-objek atau konsep-konsep yang ada di ruang masalah.

Gilang Ryan Fernandes, Sistem Penjualan dan ... 
2. Proses untuk menentukan objekobjek potensial yang ada dalam sistem dan mendeskripsikan karakterisitik dan hubungannya.

3. Aplikasi konsep berorientasi objek untuk memodelkan permasalahan dan sistem, baik untuk lingkup perangkat lunak maupun nonperangkat lunak [3].

\section{Tinjauan Organisasi}

Organisasi adalah suatu tempat berkumpulnya sejumlah orang yang saling terkait dalam mencapai suatu tujuan tertentu yang telah disepakati bersama dan untuk mewujudkannya diperlukan adanya pengorganisasian. Adapun struktur organisasi pada restoran Martabak Kubang adalah sebagai berikut:

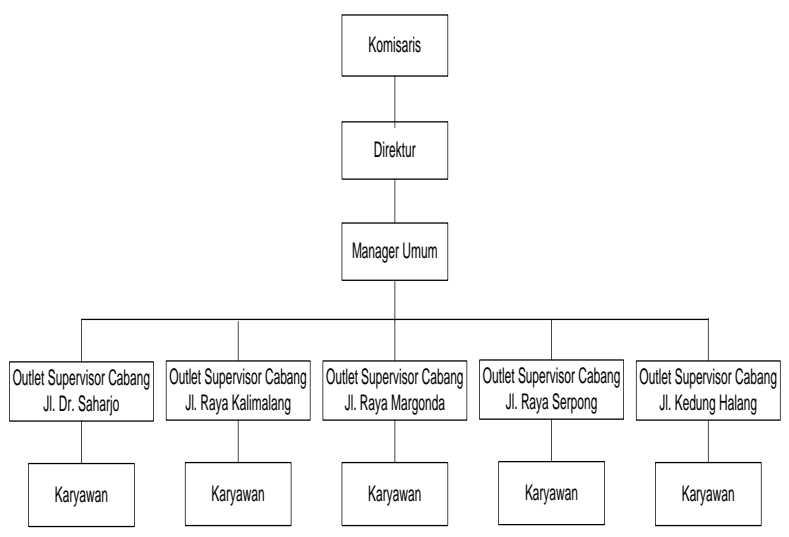

\section{Gambar 1. Struktur Organisasi Restoran Martabak Kubang}

\section{E. Analisa Sistem}

Analisa sistem akan membantu dan mengetahui informasi-informasi tentang sistem yang sedang berjalan dan bagaimana mencari solusi terhadap kebutuhan-kebutuhan yang belum bisa terpenuhi sehingga bisa diterapkan dalam tahap perancangan sistem.

\section{F. Uraian Prosedur}

Urutan-urutan prosedur pada proses penjualan restoran Martabak Kubang Jalan Raya Kalimalang, Jakarta Timur adalah sebagai berikut:

\section{Proses Pemesanan Langsung}

Pelanggan datang langsung ke restoran Martabak Kubang kemudian memesan produk berdasarkan daftar menu yang terdapat di restoran. Setelah itu kasir mencatat daftar menu yang diinginkan pelanggan dan membacakan ulang (verifikasi) daftar tersebut kepada pelanggan. Jika catatan kasir salah, maka pelanggan memberitahukan kepada kasir bahwa pesanan salah dan kasir membenarkan. Diakhiri proses pemesanan, kasir memberikan menu tersebut kepada staf, kemudian staf membuat produk makanan/minuman (daftar menu pesanan) lalu memberikan produk tersebut kepada pelanggan.

2. Proses Pemesanan Delivery

Pelanggan melakukan pemesanan via telepon kemudian kasir menulis pesanan sesuai dengan pesanan pelanggan dan menanyakan alamat tujuan dan nomer telepon yang bisa dihubungi, kemudian mencatatnya di selembar kertas. Setelah itu kasir memberi pesanan kepada staf, kemudian staf membuat produk/menu sesuai pesanan dan memberikan pesanannya kepada kasir kemudian kasir membuatkan nota pemesanan delivery, lalu kasir memberikan nota pesananya kepada kurir di sertakan dengan catatan selembar kertas yg berisi alamat dan nomer telepon pelanggan agar pesanan dapat diantar oleh kurir dengan tepat.

3. Proses Pembayaran Tunai

Kasir memberikan nota pemesanan kepada pelanggan kemudian pelanggan melakukan pembayaran sesuai dengan pesanannya.

4. Proses Pembayaran Delivery

Kurir memberikan pesanan dan nota kepada pelanggan agar dapat melakukan proses pembayaran sesuai pesanannya. 
5. Proses Laporan

Kasir memberikan nota-nota transaksi non delivery dan nota-nota transaksi delivery kemudian diserahkan kepada pimpinan.

\section{G. Analisa Proses}

Analisa proses yaitu menganalisa proses bisnis dan aktivitas yang sedang berjalan. Disini penulis menggunakan Activity Diagram yang bertujuan untuk melihat proses bisnis yang sedang berjalan pada restoran martabak kubang, berikut adalah beberapa Activity Diagram:

1. Activity Diagram Proses Pemesanan Langsung

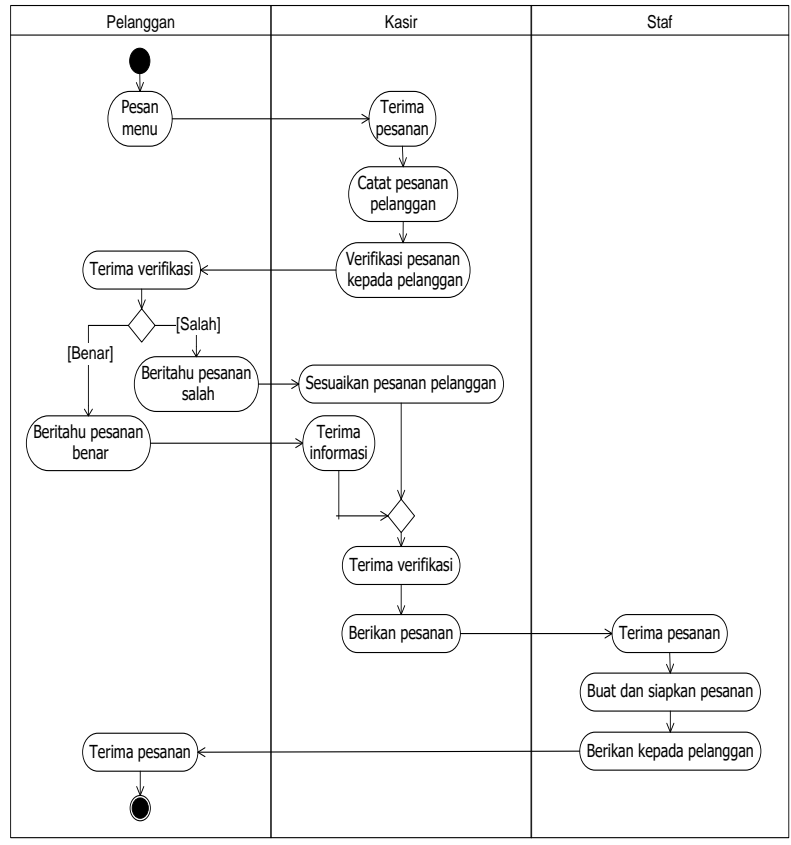

\section{Gambar 2. Activity Diagram Proses} Pemesanan Langsung
2. Activity Diagram Proses Pemesanan Delivery

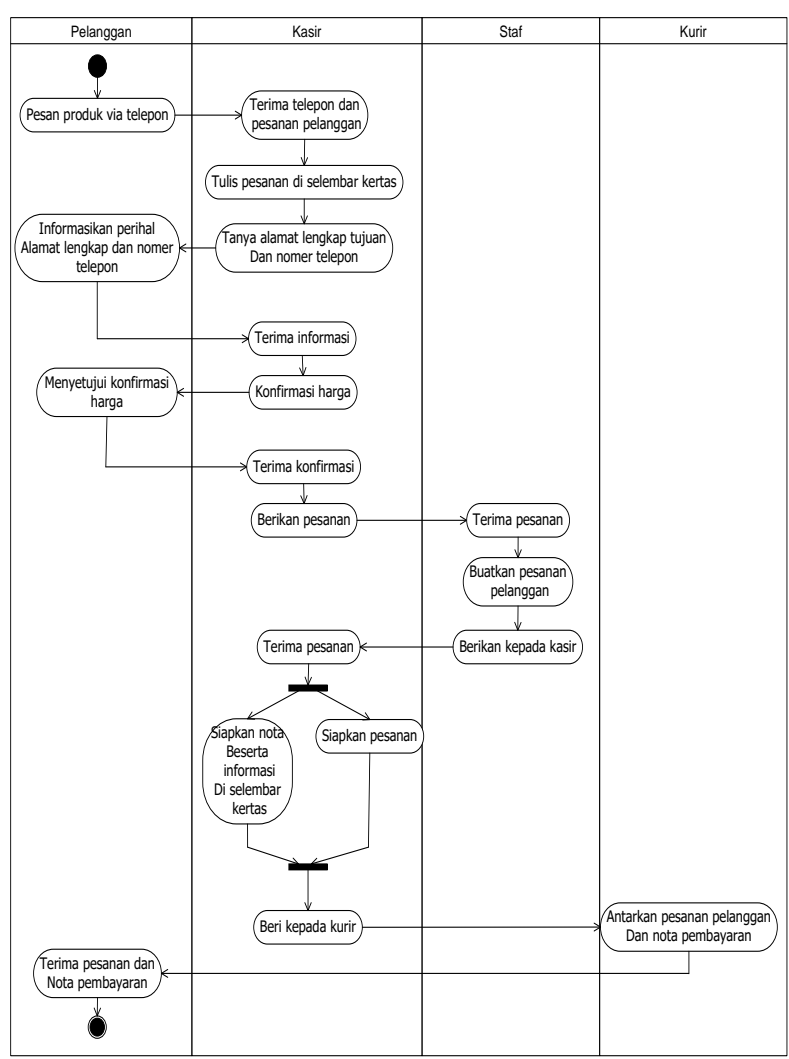

Gambar 3. Activity Diagram Proses Pemesanan Delivery

\section{H. Analisa Masalah}

Analisa masalah adalah menganalisa permasalahan yang dihadapi pada sistem yang sedang berjalan pada restoran Martabak Kubang, analisa masalah ini menggunakan Fishbone Diagram, diantaranya adalah sebagai berikut: 


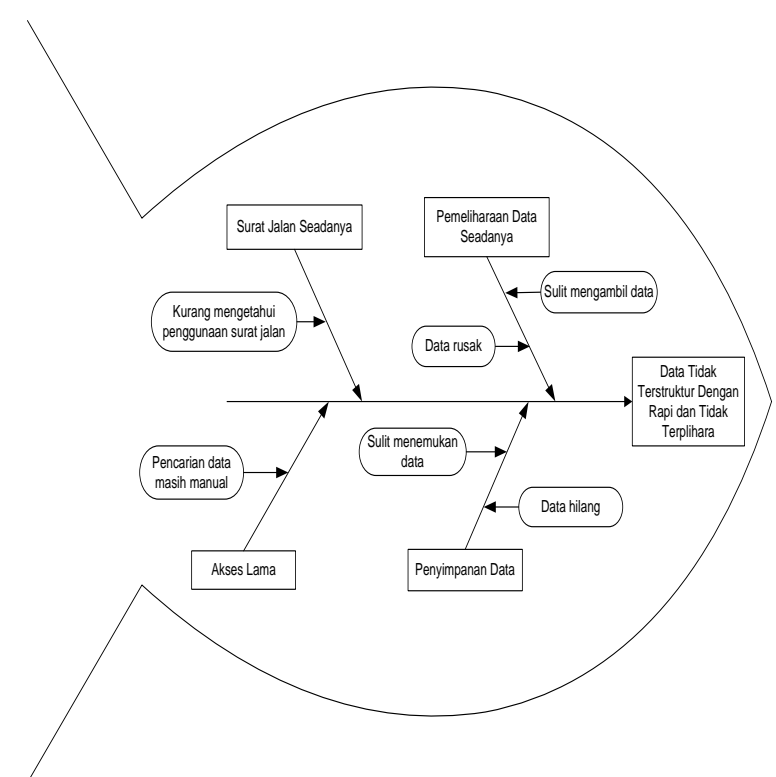

Gambar 4. Fishbone Diagram

Diagram ini akan menunjukkan sebuah dampak atau akibat dari sebuah permasalahan, dengan berbagai penyebabnya. Efek atau akibat dituliskan sebagai moncong kepala. Sedangkan tulang ikan diisi oleh sebabsebab sesuai dengan pendekatan permasalahannya [4].

\section{Package Diagram}

Package diagram adalah diagram rancangan kebutuhan sistem penjualan dan delivery pada restoran Martabak Kubang, yaitu sebagai berikut:
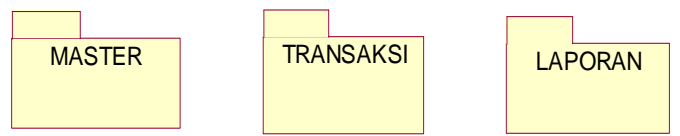

Gambar 5. Package Diagram

\section{J. Use Case Diagram}

Use Case Diagram merupakan deskripsi fungsi sebuah sistem dari perspektif pengguna. Use case bekerja dengan cara mendeskripsikan tipikal interaksi antara pengguna sebuah sistem dengan sistem yang dipakai, berikut adalah Use Case Diagram pada restoran Martabak Kubang:

\section{Use Case Diagram Master}

Berikut ini adalah tampilan Use Case Diagram Master :

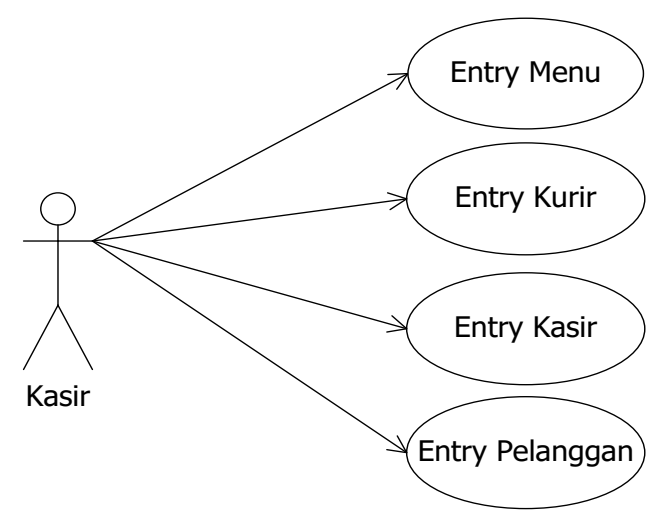

Gambar 6. Use Case Diagram Master

2. Use Case Diagram Transaksi Berikut ini adalah tampilan Use Case Diagram Transaksi :

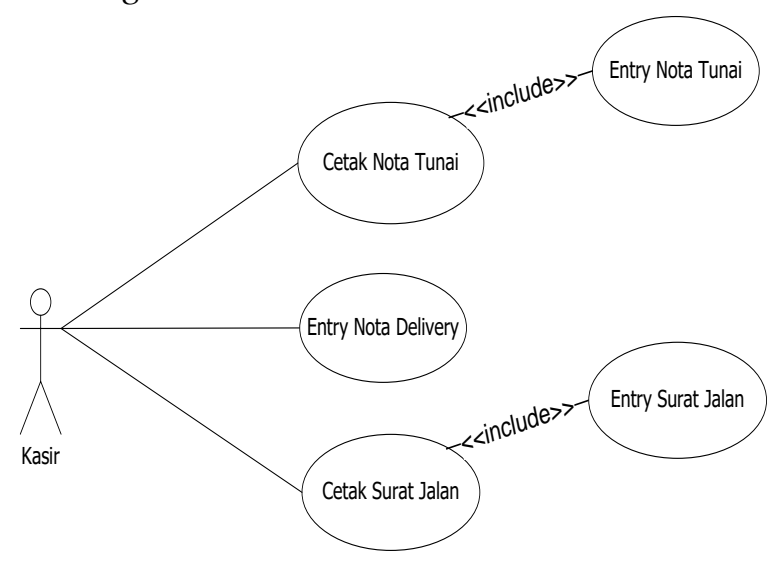

Gambar 7. Use Case Diagram Transaksi

3. Use Case Diagram Laporan Berikut ini adalah tampilan Use Case Diagram Master : 


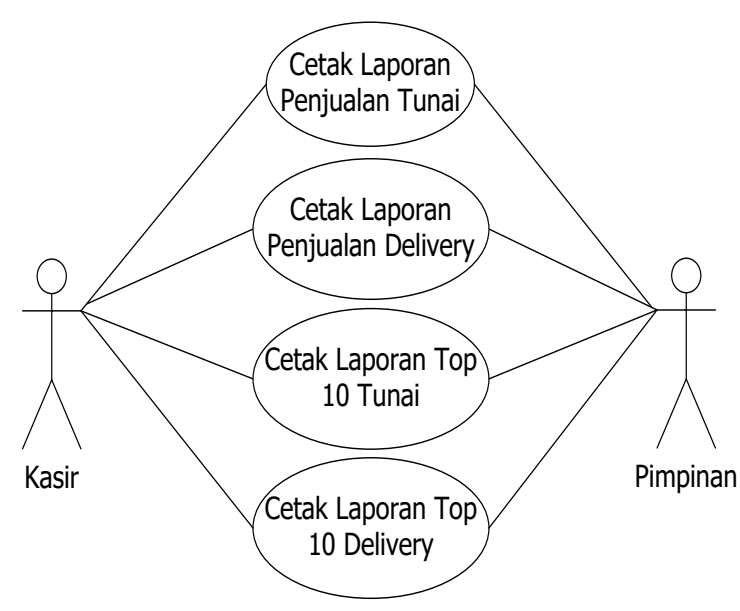

Gambar 8. Use Case Diagram Laporan

\section{HASIL DAN PEMBAHASAN}

\section{A. Rancangan Basis Data}

Untuk melakukan rancangan basis data yaitu dengan membuat ERD (Entity Relationship Diagram) berdasarkan analisa, transformasi diagram ERD menjadi bentuk LRS (Logical Record Structured), gambaran LRS kemudian menormalisasi basis data sehingga benar-benar sedikit kemungkinan munculnya duplikasi data dan membuat spesifikasi basis data.

\section{ERD}

Entity Relationship Diagram martabak kubang berdasarkan kebutuhan user. Entity Relationship Diagram (ERD) merupakan suatu model data yang dikembangkan berdasarkan objek [6].

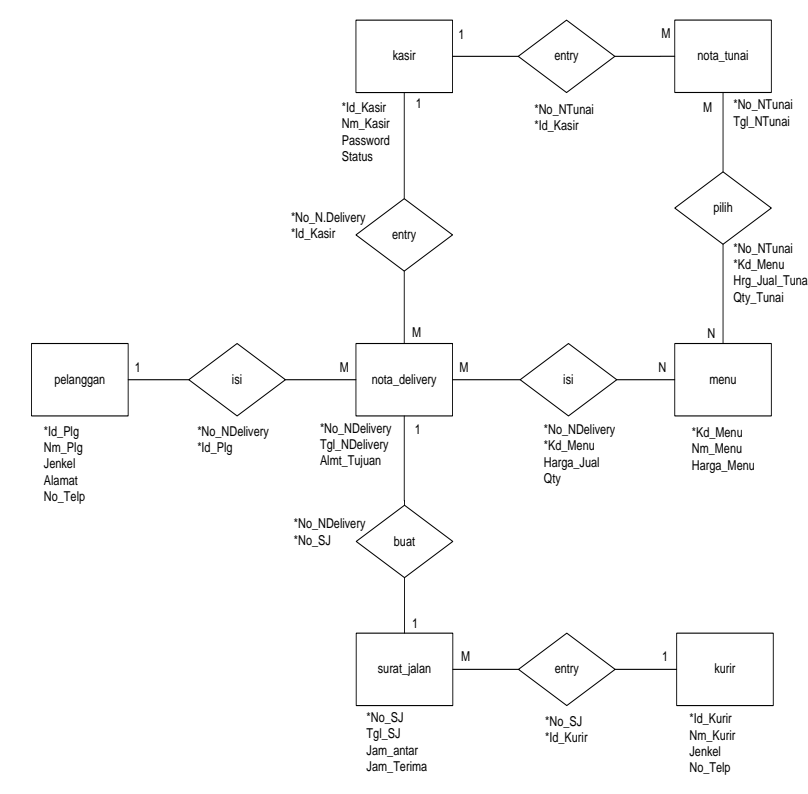

Gambar 9. Entity Relationship Diagram

2. Transformasi $E R-D$ ke $L R S$

Setelah membuat ERD maka selanjutnya ialah Transformasi ERD yang kemudian setelah itu lanjut kepada perancangan Logical Record Structure

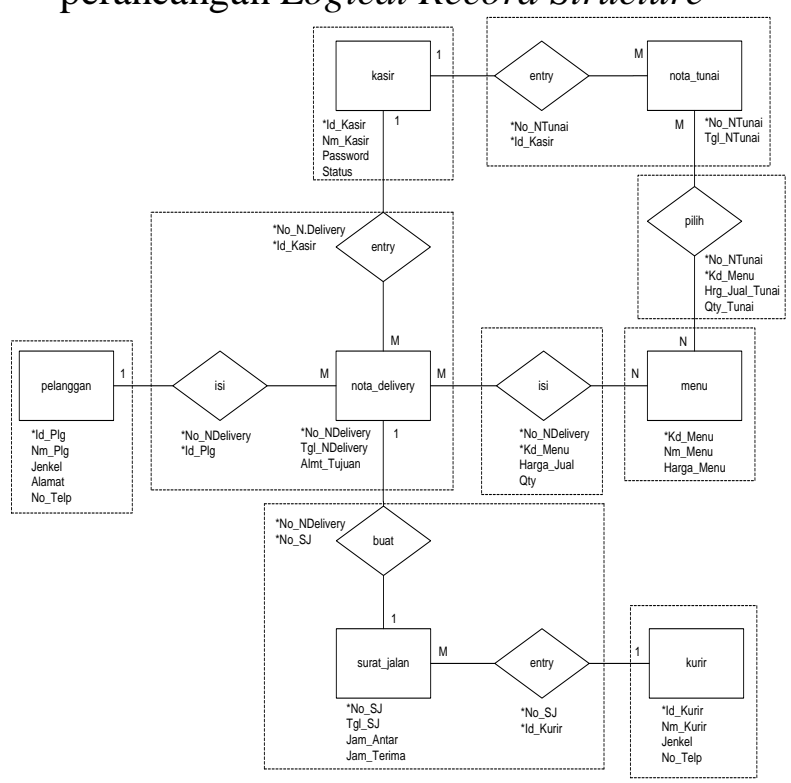

Gambar 10. Transformasi ER-D Ke Logical Record Structure

3. Logical Record Structure (LRS)

Pada pembuatan $L R S$ sangat bergantung dalam Transformasi ERD. Berikut adalah rancangan $L R S$ : 


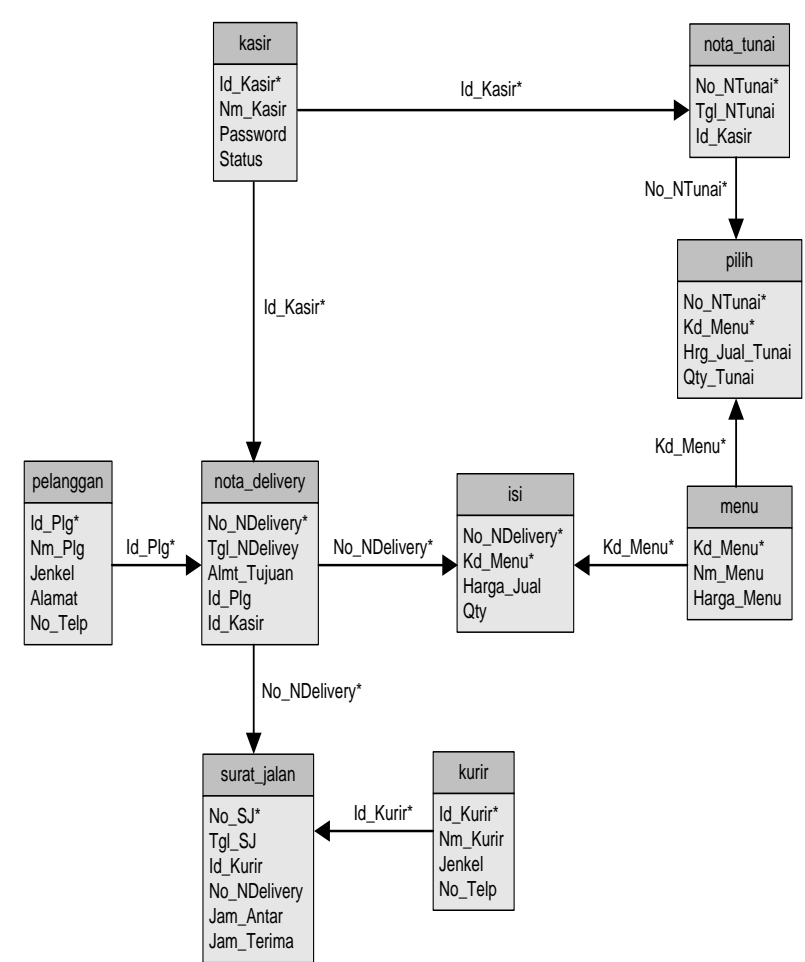

Gambar 11. Logical Record Structure

Setelah ini kemudian dibuat database berdasarkan dengan $L R S$ diatas dengan Menggunakan MySQL. MySQL adalah sebuah basis data yang mengandung satu atau jumlah tabel. Tabel terdiri atas sejumlah baris dan setiap baris menggandung satu atau sejumlah tabel. Tabel terdiri atas sejumlah baris dan setiap baris mengandung satu atau sejumlah tabel [5].

\section{B. Rancangan Antar Muka}

1. Rancangan Dialog Layar

a) Struktur Tampilan

Berikut ini adalah rancangan struktur tampilan sistem :

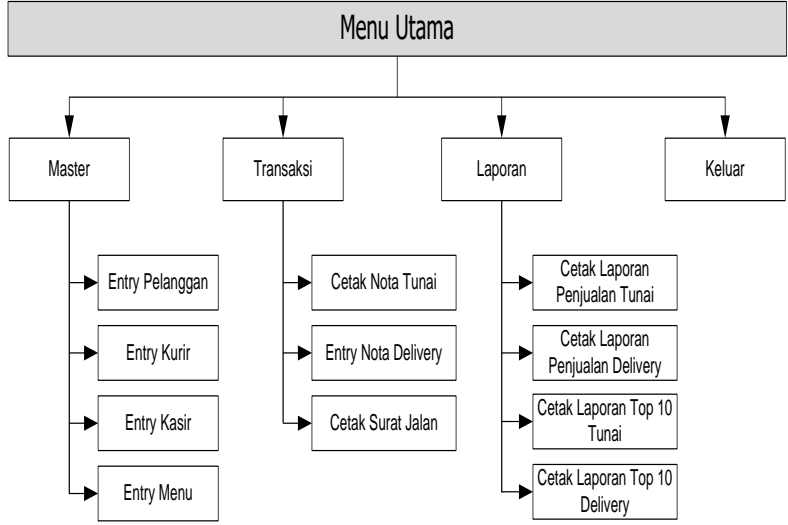

\section{Gambar 12. Struktur Tampilan}

b) Rancangan Layar

1) Rancangan layar Form Menu Utama Berikut adalah Rancangan layar Form Menu Utama yang berisikan Master, Transaksi, Laporan dan Keluar.

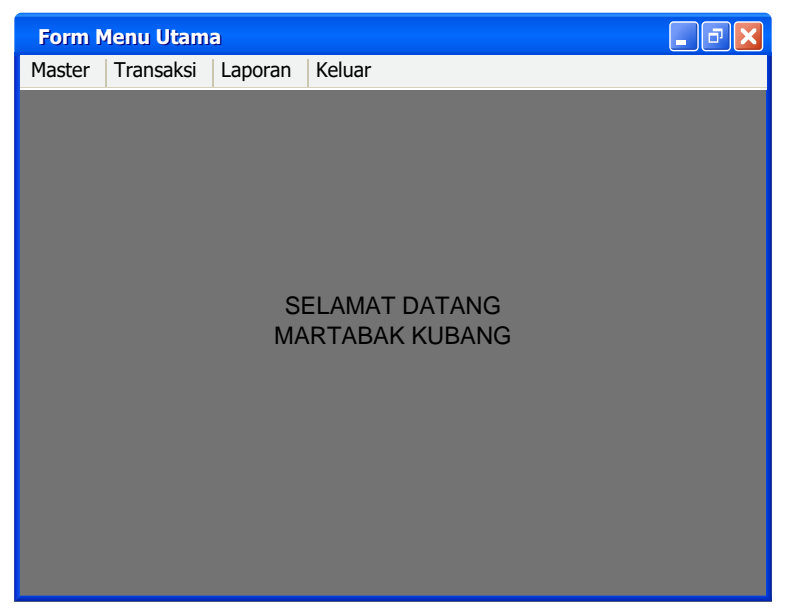

Gambar 13: Rancangan Layar Form Menu Utama

2) Rancangan Layar Form Menu Utama Master

Berikut Rancangan Layar Form Menu Utama Maste, terdapat entry pelanggan, entry kurir, entry kasir dan entry menu. 


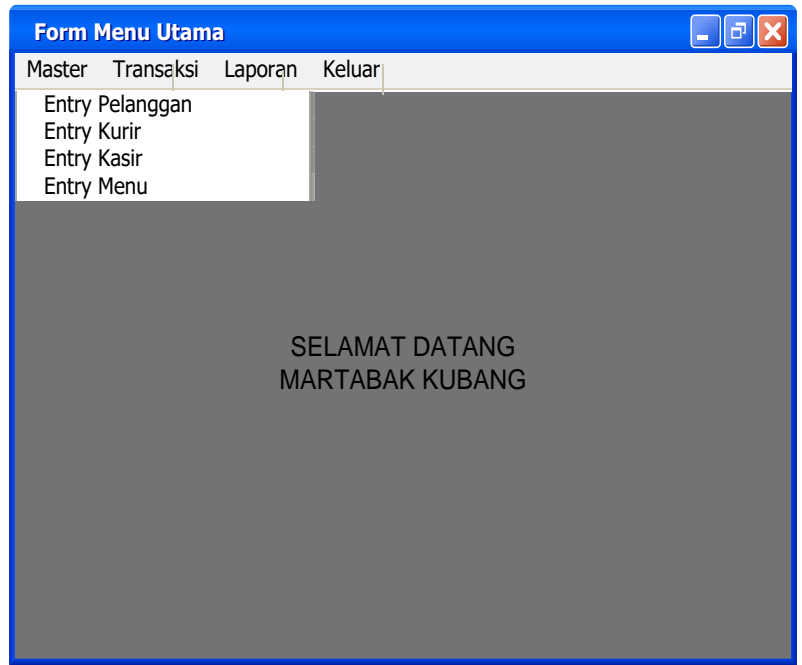

Gambar 14: Rancangan Layar Form Menu Utama Master

3) Rancangan Layar Form Entry

Pelanggan

Berikut Rancangan Layar Form Entry Pelanggan yang bertujuan untuk menginput atau mengentry data pelanggan.

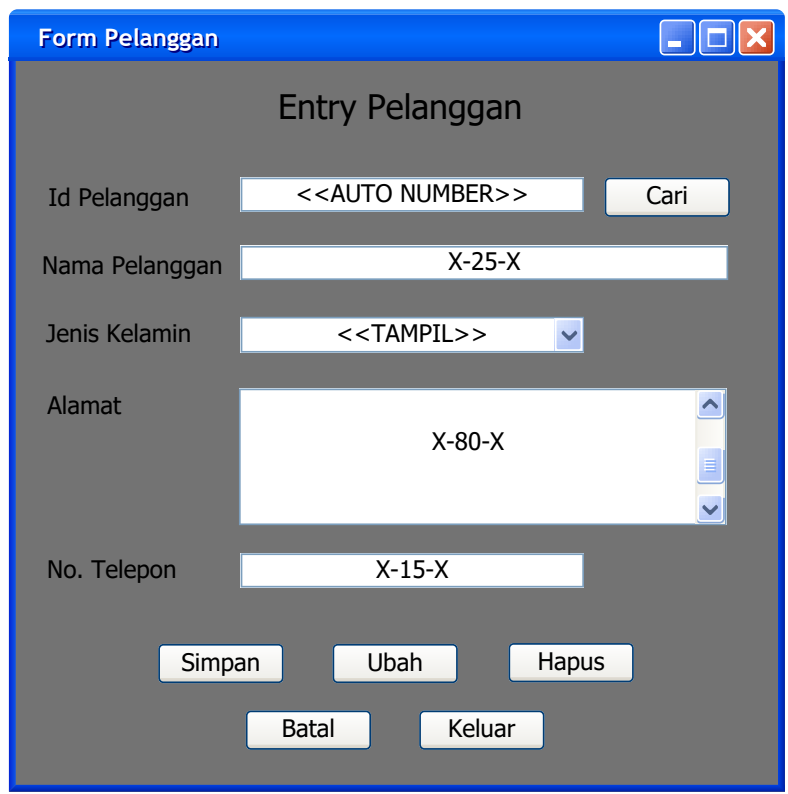

Gambar 15. Rancangan Layar Form Entry Pelanggan

4) Rancangan Layar Form Menu Utama Transaksi

Berikut Rancangan Layar Form Menu Utama Transaksi, terdapat cetak nota tunai, entry nota delivery dan cetak surat jalan.

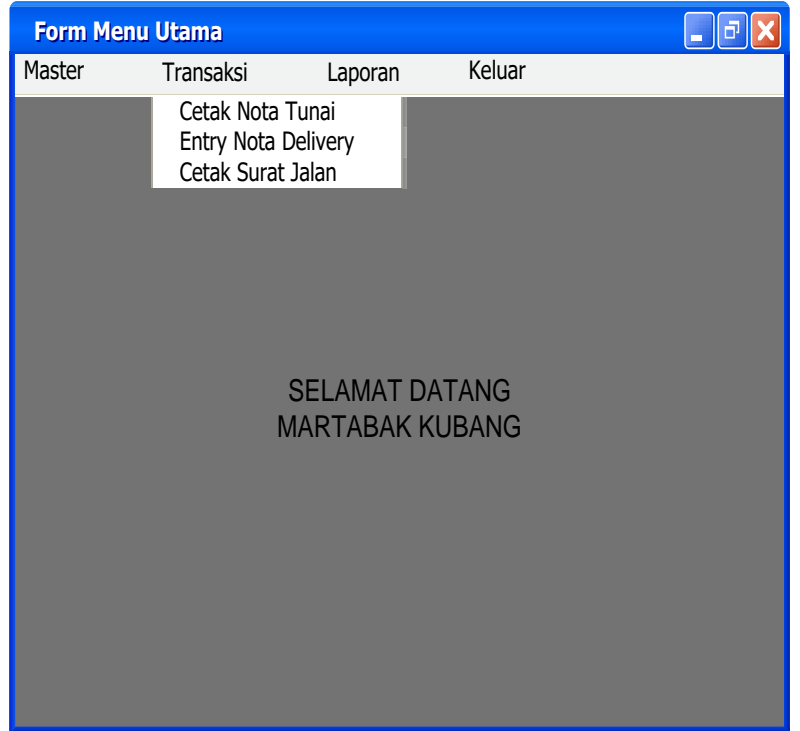

Gambar 16: Rancangan Layar Form Menu Utama Transaksi

5) Rancangan Layar Form Entry Nota Delivery

Berikut Rancangan Layar Form Entry Nota Delivery yang bertujuan untuk mengentry semua data-data yang berkaitan dengan nota delivery, seperti data pelanggan, kasir dan menu.

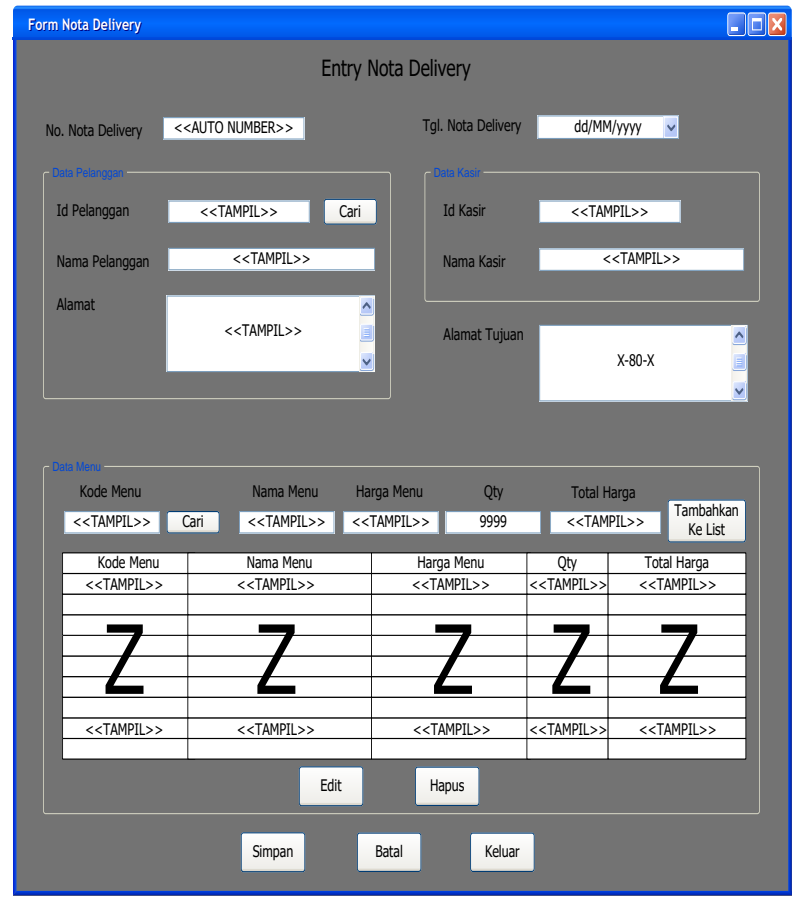

Gambar 17. Rancangan Layar Form Entry Nota Delivery 
6) Rancangan Layar Form Menu Utama Laporan

Berikut Rancangan Layar Form Menu Utama Laporan, terdapat cetak laporan penjualan tunai, cetak laporan penjualan delivery, cetak laporan top 10 tunai dan cetak laporan top 10 Delivery.

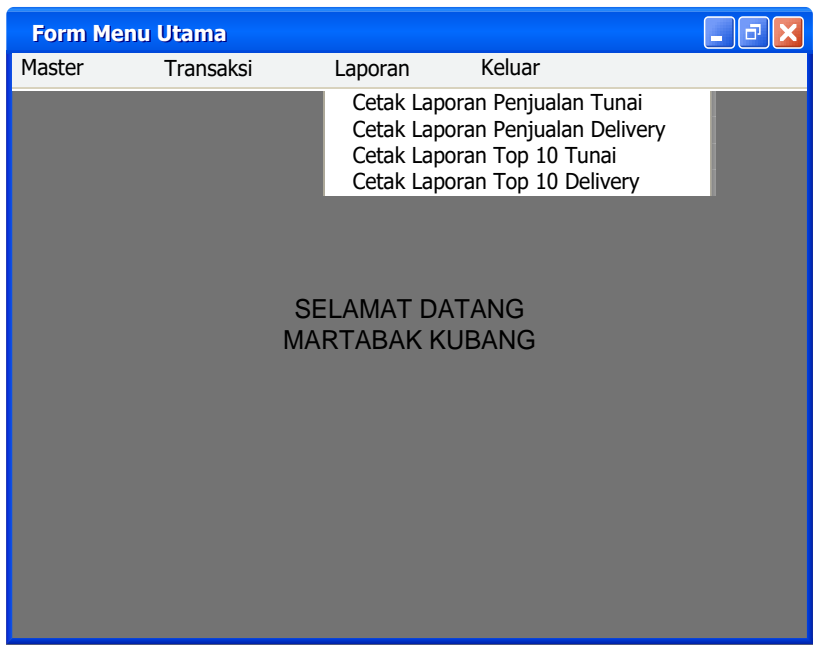

Gambar 18: Rancangan Layar Form Menu Utama Laporan

7) Rancangan Layar Form Cetak Laporan Penjualan Tunai

Berikut adalah Rancangan Layar Form Cetak Laporan Penjualan Tunai yang berfungsi atau bertujuan untuk melihat hasil atau total penjualan tunai.

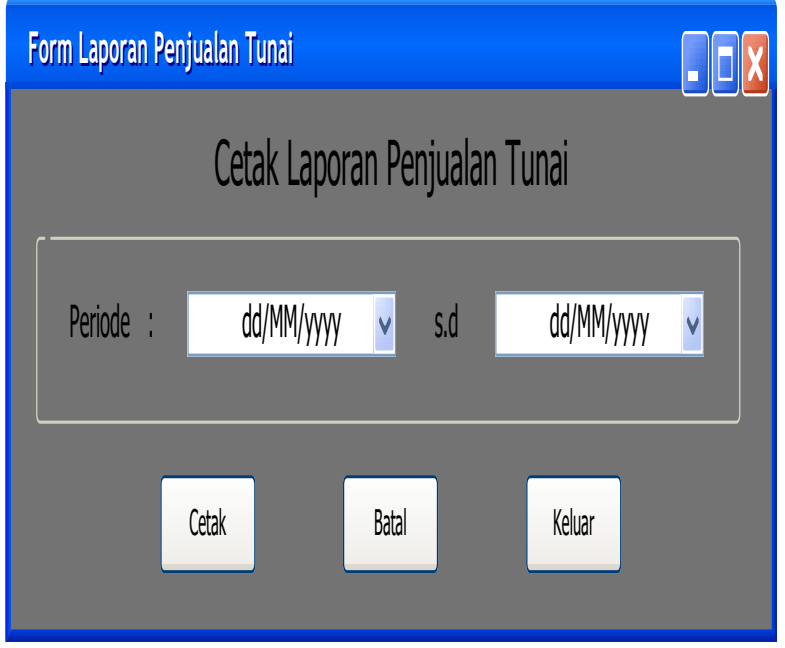

Gambar 19. Rancangan Layar Form Cetak Laporan Penjualan Tunai

\section{Sequence Diagram}

Sequence Diagram adalah perancangan form/layar (visual coding). Biasanya digunakan untuk tujuan analisa dan desain dan memfokuskan identifikasi metoda di dalam sebuah sistem.

1. Sequence Diagram Form Entry Data Pelanggan

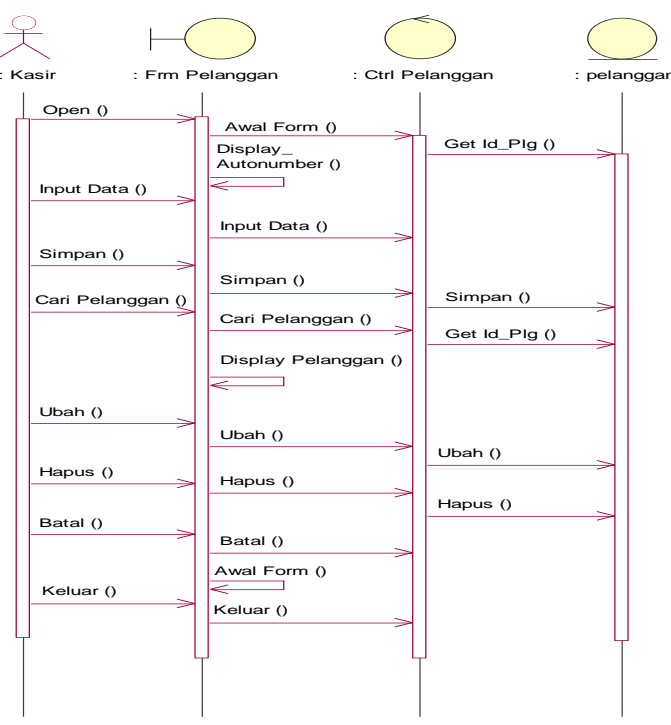

\section{Gambar 20. Sequence Diagram Form Entry Data Pelanggan}

2. Sequence Diagram Form Entry Nota Delivery

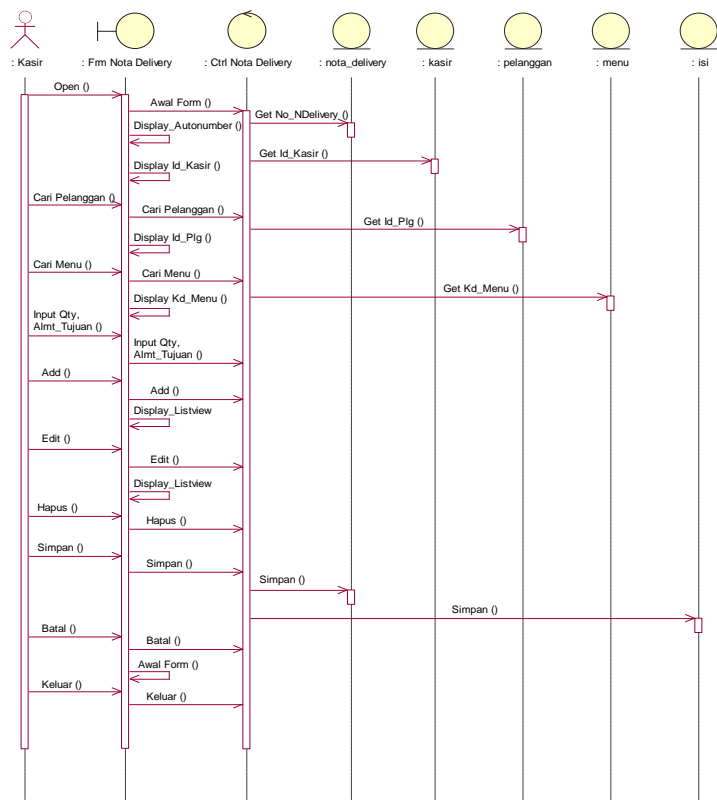

Gambar 21. Sequence Diagram
Form Entry Nota Delivery 
3. Sequence Diagram Form Cetak Laporan Penjualan Tunai

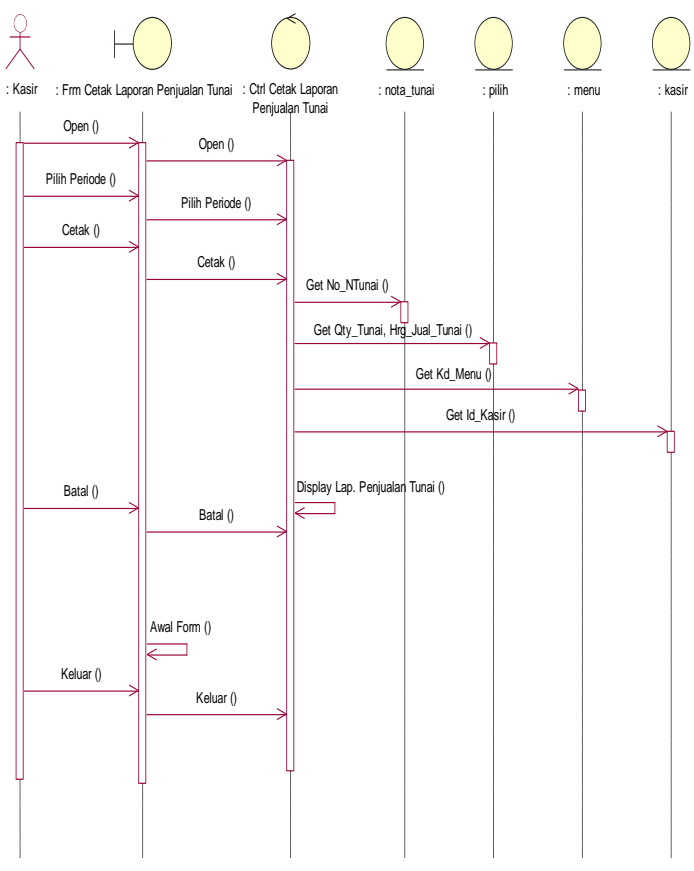

Gambar 22. Sequence Diagram Form Cetak Laporan Penjualan Tunai

\section{SIMPULAN}

Berdasarkan analisa yang telah dilakukan maka perancangan sistem Penjualan dan Delivery pada Restoran Martabak Kubang dapat dijadikan sebagai salah satu solusi yang tepat untuk meningkatkan kinerja pada bagian penjualan dan delivery-nya. Sehingga dapat diambil kesimpulannya sebagai berikut:

a. Pengunaan sistem dapat membantu proses-proses pengolahan data, sehingga kekurangan pada sistem yang lama dapat teratasi.

b. Pemeliharaan data yang baik dan terstruktur, sehingga mempermudah pemilik perusahaan untuk memperoleh data guna pengambilan keputusan.

c. Sistem dapat membantu menangani proses-proses yang membutuhkan kehandalan data seperti pada saat penjualan dan delivery.

d. Mengefisiensikan waktu dan meningkatkan keakuratan data yang dapat meminimalisir tingkat kesalahankesalahan yang terjadi pada saat sistem masih berjalan secara manual.

e. Mencetak laporan-laporan transaksi dan surat jalan, sehingga dapat mengetahui penjualan secara benar serta terlihat lebih rapi dan jelas.

\section{DAFTAR PUSTAKA}

[1] O'Brien dan Marakas. Introduction to Information Systems. (12th Edition). McGraw-Hill, 2008.

[2] Weli. Tinjauan Teoritis Tentang Migrasi Sistem Informasi Akuntansi Pendekatan Relasional ke Pendekatan Objek. Seminar Nasional Aplikasi Teknologi Informasi 2006 (SNATI 2006), 2006; ISSN : 1907-5022 : E1 - E6

[3] Diakses dari Warbrain, Analisis Berorientasi Objek, untuk web: http://warbrainhkr.blogspot.com/2013/03/a.html (diakses 22 Februari 2017)

[4] Diakses dari Noviwilyaini. Pengertian Diagram Ishikawa, untuk web: http://noviwilyaini.wordpress.com/ 2013/10/14/pengertian-diagramishikawa/ (diakses 22 Februari 2017)

[5] Kustiyahningsih, Yeni \& Devie, Rosa. Pemrograman Basis Data Berbasis Web menggunakan PHP \& MySQL. Yogyakarta: Graha Ilmu, 2011.

[6] Sutanta, Edhy. 2011. Basis Data Dalam Tinjauan Konseptual. Yogyakarta : Andi Offset 